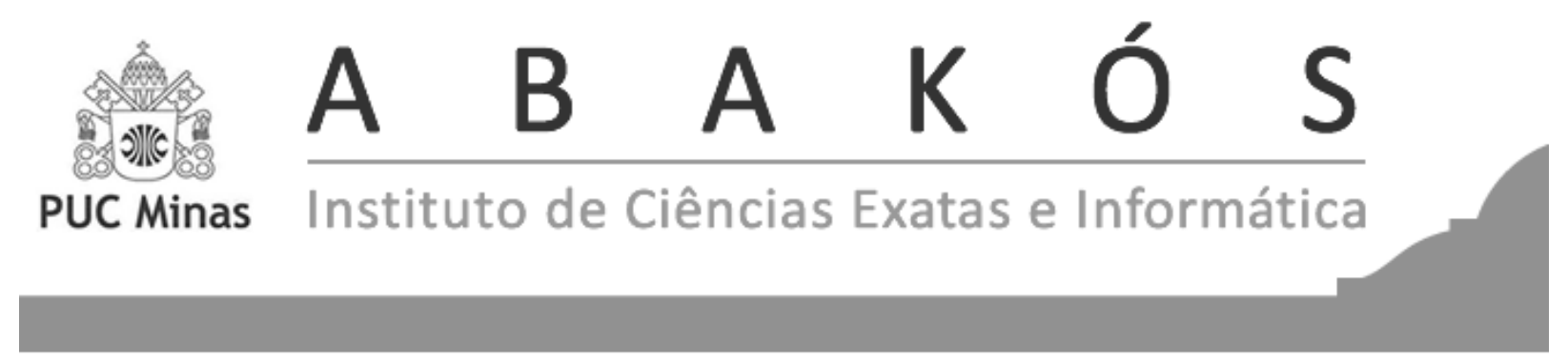

cc) (†)

\title{
Ensino da Análise Combinatória por meio de Tecnologia Móvel: um relato de experiência*
}

Teaching Combinatory Analysis by Mobile Technology: an experience report

\author{
Paulo Cezar Monteiro Tavares ${ }^{1}$ \\ Tânia Fernandes Bogutchi ${ }^{2}$
}

\begin{abstract}
Resumo
O ensino da Análise Combinatória nas escolas brasileiras, no início do século XXI, baseiase, geralmente, na utilização de fórmulas matemáticas. O presente trabalho se dispõe a propor uma estratégia didática que possa contribuir para o ensino desse conteúdo por meio de uma abordagem, que prioriza o raciocínio antes do conhecimento formalizado. Nessa pesquisa foi desenvolvido um aplicativo para smartphone, utilizando a plataforma Android Studio, com a criação de um jogo para o ensino de Análise Combinatória para a Educação Básica. O uso desse aplicativo tem como suporte uma sequência didática elaborada com desafios que envolvem problemas de contagem, atraindo, assim, a atenção dos alunos e favorecendo o processo de construção do seu conhecimento. O jogo foi aplicado nos alunos do segundo ano do Ensino Médio da Escola Educação Criativa, localizada no município de Ipatinga, MG. Ao final do processo da aprendizagem, utilizando essa técnica, os alunos expressaram suas opiniões e críticas respondendo a um questionário semi-estruturado. Por meio desse estudo, foi possível verificar que novas metodologias de ensino, aliadas ao uso de tecnologias, podem contribuir para o ensino de Matemática, especialmente para o de Análise Combinatória.
\end{abstract}

Palavras-chave: Educação Matemática. Análise Combinatória. Jogos. Tecnologia no Ensino.

\footnotetext{
* Submetido em 23/11/2017 - Aceito em 10/06/2019

${ }^{1}$ Mestre em Ensino de Ciências e Matemática pela PUC Minas, Brasil-cezar.monteiro@gmail.com

${ }^{2}$ Doutorado em Geografia: Tratamento da Informação Espacial da PUC Minas, Brasil- bogutchi@pucminas.br
} 


\begin{abstract}
The teaching of Combinatorial Analysis in Brazilian schools, at the beginning of the 21st century, is generally based on the use of mathematical formulas. The present work proposes a didactic strategy that can contribute to the teaching of this content through an approach that prioritizes the reasoning before formalized knowledge. In this research, we developed an application for smartphone, using the platform Android Studio, with the creation of a game for teaching Combinatorial Analysis for Basic Education. The use of this application is supported by a didactic sequence elaborated with challenges that involve problems of counting, thus attracting students' attention and favoring the process of building their knowledge. The game was applied to students of the second year of high school in a private school, in the city of Ipatinga, MG. At the end of the learning process using this technique, the students expressed their opinions and criticisms by responding to a semi-structured questionnaire. Through this study, it was possible to verify that new teaching methodologies combined with the use of technologies can contribute to Mathematics Education, especially to Combinatorial Analysis.
\end{abstract}

Keywords: Mathematics Education. Combinatorial Analysis. Games. Technology in teaching. 


\section{INTRODUÇÃO}

No contexto do ensino de Matemática na Educação Básica no Brasil, especialmente sobre o ensino de Análise Combinatória, o cenário apresenta de um modo geral, o desinteresse dos alunos em aprender tal assunto. Essa é uma realidade vivida pelo autor desta pesquisa. Sendo professor desse conteúdo para alunos do Ensino Médio de uma escola privada, no município de Ipatinga, em Minas Gerais, tal desinteresse tem conduzido esses alunos.

Outra realidade vivida pelo professor-pesquisador é o uso de smartphone por parte dos alunos durante as aulas, para o acesso às redes sociais, jogos, dentre outras, por meio da Internet, o qual prejudica o aprendizado durante as aulas.

Diante desse panorama atual e dos desafios a serem vencidos, surgem alguns questionamentos: (1) De que maneira a utilização de novas tecnologias pode contribuir para o ensino da Análise Combinatória? (2) Entre tantos recursos tecnológicos, qual a melhor escolha para o ensino e resolução de problemas envolvendo contagem?

Para o uso de novas tecnologias, a resposta surge de Cavalcante (2010), pois, para ele, a Matemática não pode ser resumida a técnicas sem nenhuma relação com o mundo atual. Ainda de acordo com Cavalcante (2010), as tendências da Educação Matemática como resolução de problemas e modelagem, entre outras existentes, se preocupam em possibilitar a atividade de ensino e de aprendizagem, com o intuito de promover mudanças sociais importantes e transformações que contribuam para um país mais justo e com menos desigualdades. Dessa maneira, não se pode ignorar que recursos tecnológicos avançados estão disponíveis para muitos jovens e adolescentes do nosso país, fazendo parte do cotidiano deles, e a escola não pode estar alheia a isso.

Com relação ao tipo de recurso, depois de leituras e análises, optou-se por um aplicativo para smartphone, utilizando o Android Studio para a realização desse trabalho. Essa plataforma é muito utilizada para desenvolvimento de aplicativos e pode ser útil na criação de produtos educacionais e Objetos de Aprendizagem (OA).

Assim, este trabalho apresentou como objetivo central investigar o uso de um aplicativo para smartphone, por alunos do Ensino Médio, em sala de aula, como alternativa para o ensino de Análise Combinatória.

\section{REVISÃO BIBLIOGRÁFICA}

O objetivo da pesquisa foi a criação de um jogo para smartphone e tablet para o ensino de Análise Combinatória, portanto, a leitura feita pelo autor foi realizada tendo como foco o ensino de Matemática por meio de resolução de problemas pela utilização de jogos, ou seja, a tecnologia na Educação e no Ensino de Matemática. 


\section{O ENSINO DE MATEMÁTICA BASEADO NA RESOLUÇÃO DE PROBLEMAS}

Tradicionalmente, o processo de ensino e aprendizagem envolvendo a Matemática baseiase, de um modo geral, na memorização de fórmulas e no desenvolvimento de algebrismos mecanizados. De acordo com Romero (2007), os conteúdos de Matemática, geralmente, são apresentados aos alunos como um interminável discurso simbólico, abstrato e incompreensível. Ainda segundo a autora, esse tipo de ensino tem se preocupado em garantir que os alunos dominem apenas técnicas e fórmulas, em vez de desenvolverem, também, a compreensão real dos conceitos relacionados a esses conteúdos.

Propostas didáticas baseadas na resolução de problemas, trabalhando o raciocínio lógico e proporcionando experiências que possam contribuir para o aprendizado do aluno são de grande importância para uma mudança da realidade apresentada nas escolas. De acordo com Lima (2011, p. 15), resolver um problema é uma atividade desafiadora. Um sujeito está diante de um problema quando se encontra em uma situação que, inicialmente, não é satisfatória e, em um primeiro momento, não encontra uma solução. O esforço por encontrar uma solução é que induz o indivíduo a criar estratégias e métodos.

Uma alternativa para este contexto é a utilização de uma das metodologias ativas para o ensino e aprendizagem, a PBL (Problem Based Learning) ou a "Aprendizagem Baseada em Resolução de Problemas". Ribeiro (2008) afirma que a PBL reúne aspectos de ensino investigados desde os anos de 1960, inicialmente na área médica, sendo uma metodologia desenvolvida em sala de aula, em qualquer disciplina, por meio de apresentação de situações-problema que iniciam, direcionam e motivam a aprendizagem de conceitos e teorias levando ao desenvolvimento de habilidades e atitudes.

O ensino de Análise Combinatória pode se beneficiar desta estratégia. Em vez de apresentar ao aluno, em um primeiro momento, conceitos e fórmulas matemáticas, a apresentação de desafios que irão atrair a atenção e o interesse do aluno pode constituir-se numa excelente estratégia no processo de ensino e aprendizagem. De acordo com Lima (2011, p. 15) "[...] se as fórmulas são apresentadas de forma pronta e acabada, os alunos ficam sem saber em qual momento deverão utilizar cada uma delas e o ensino da análise combinatória torna-se tecnicista e operacional".

\section{O ENSINO DE MATEMÁTICA POR MEIO DE JOGOS}

A estratégia baseada na resolução de problemas pode ser uma boa medida para promover mudanças no processo de ensino e aprendizagem da Matemática nas escolas, e a utilização de jogos com essa finalidade pode enriquecer e contribuir para essa metodologia. A palavra jogo, do latim locus, significa, etimologicamente, gracejo e zombaria, sendo empregada no lugar de ludus, que representa brinquedo, jogo, divertimento e passatempo (SANTOS, 2010).

De acordo com Barbosa e CARVALHO (2008), dentro da resolução de problemas, a 
introdução de jogos como estratégia do processo de ensino e aprendizagem na escola é um recurso pedagógico que apresenta bons resultados. Esse recurso cria situações que permitem ao aluno desenvolver métodos próprios para resolver problemas, além de estimular sua criatividade em um ambiente desafiador e ao mesmo tempo gerador de motivação. Esse cenário favorece o aprendizado do aluno.citarLivro

Cabral (2006) menciona que a justificativa para o uso do jogo no ensino de Matemática está na possibilidade de introduzir uma linguagem matemática que gradativamente será incorporada aos conceitos matemáticos formais, à medida que se desenvolve a capacidade de lidar com informações e de criar significados culturais para os conceitos matemáticos e estudo de novos conteúdos.

É importante destacar que alguns cuidados devem ser tomados quando o assunto é a utilização de jogos em sala de aula. Ainda segundo Cabral (2006), se a motivação for equivocada, numa tentativa de trazer apenas o lúdico para dentro da sala de aula, não trará resultados benéficos para o aprendizado. Entretanto o jogo, se convenientemente planejado, pode ser um recurso pedagógico eficaz para a construção do conhecimento matemático.

\section{A TECNOLOGIA NA EDUCAÇÃO E NO ENSINO dE MATEMÁTICA}

Segundo Perius (2012), o avanço tecnológico tem influenciado muito a vida das pessoas, ditando modos e comportamentos, criando inovações e conhecimentos diversos. Nesse contexto, é oportuno destacar a utilização da tecnologia móvel, pois smartphone e tablet são cada vez mais comuns no cotidiano das pessoas. Suas funções auxiliam na execução de tarefas e tornam práticas a realização de determinadas atividades. No âmbito escolar, esses recursos podem ser úteis no processo de ensino e aprendizagem. De acordo com UNESCO (2014), tablet e smartphone são utilizados por alunos e educadores em todo o mundo para acessar informações, racionalizar e simplificar a administração, tornando-se, portanto, ferramentas que podem auxiliar no processo de ensino e aprendizagem.

Mesmo com tantos recursos que podem ser utilizados no ensino, o professor continua tendo um papel importante no processo de ensino e aprendizagem. É oportuno destacar que o docente nunca será substituído pela tecnologia. Este fato corrobora Jucá (2006), que diz:

As novas tecnologias não dispensam a figura do professor, pelo contrário, exigem deste, que adicione ao seu perfil novas exigências mais complexas tais como: saber lidar com os ritmos individuais de seus alunos, apropriar-se de técnicas novas de elaboração de material didático produzidos por meios eletrônicos, trabalhar em ambientes virtuais diferentes daqueles do ensino tradicional [...], adquirir uma nova linguagem e saber manejar criativamente a oferta tecnológica (JUCÁ, 2006, p. 23)

No que diz respeito ao uso da tecnologia no ensino da Matemática, as questões aqui discutidas são pertinentes. Para D’Ambrosio (2014) no decorrer da história da humanidade, 
Matemática e Tecnologia se desenvolveram numa associação muito íntima, que pode ser caracterizada como simbiótica. A tecnologia, entendida como convergência do saber (ciência) e do fazer (técnica), e a Matemática são intrínsecas na busca solidária do sobreviver e do transcender. O conhecimento matemático não pode ser separado da tecnologia disponível.

\section{A METODOLOGIA DA PESQUISA}

Para a realização deste processo investigativo e coleta de dados, optou-se pela utilização da pesquisa-ação. Segundo Fiorentini e Lorenzato (2012), nela o pesquisador entra no ambiente a ser estudado não só para observar e compreender, mas, especialmente, para contribuir com mudanças que irão promover melhorias das práticas e dar mais liberdade de ação e de aprendizagem aos participantes. A pesquisa-ação é um processo investigativo de intervenção em que a prática investigativa, a prática reflexiva e a prática educativa caminham juntas.

Portanto, com a pesquisa-ação servindo de base, essa pesquisa foi desenvolvida a partir das seguintes etapas: (a) Identificação das possíveis abordagens metodológicas que podem ser utilizadas no ensino de Análise Combinatória; (b) Criação das atividades relativas à Análise Combinatória e organização de uma sequência didática utilizando essas atividades; (c) Análise e verificação da plataforma de programação adequada para a criação de um aplicativo para smartphone utilizando a sequência didática; (d) Criação de um aplicativo para smartphone, na forma de jogo (específico para Android) com atividades interativas orientadas como parte de uma sequência didática; (e) Aplicação do jogo criado para alunos do segundo ano do Ensino Médio de uma escola particular de Ipatinga; (f) Elaboração e aplicação de um questionário para os alunos que participaram da pesquisa com o intuito de perceber as contribuições do aplicativo na construção dos conceitos, na contextualização, na percepção das dificuldades encontradas, na proposição de melhorias, dentre outras; (g) Reformulação do aplicativo, de acordo com o resultado do questionário respondido pelos alunos.

A sequência de atividades didáticas foi elaborada a partir de uma série de desafios em problemas envolvendo aspectos de Análise Combinatória, organizados de modo adequado, tendo em vista sua consistência e a motivação do usuário. Em um segundo momento, foi elaborado um aplicativo em forma de jogo para reproduzir esta sequência de atividades de maneira mais atraente.

É importante destacar que a intenção inicial para a criação de cada desafio era de que cada aluno tivesse condições de resolvê-lo, sem a necessidade de uma visão formal e teórica sobre Análise Combinatória e de suas relações matemáticas, pois o objetivo principal era que os alunos aprendessem utilizando o raciocínio em detrimento a um processo de memorização.

O próximo passo foi a criação de um aplicativo para Android, no formato de um jogo. $\mathrm{O}$ processo se iniciou no final do mês de maio de 2016, em uma reunião com um grupo de quatro alunos do curso de Sistemas de Informação da Universidade Federal de Ouro Preto (UFOP). Nessa reunião, foi feita uma parceria entre os alunos com o professor-pesquisador, para a ela- 
boração do aplicativo. O Android Studio foi definido como o ambiente de programação.

Segundo Silva (2013), Android Studio é uma plataforma aberta voltada para dispositivos móveis que foi desenvolvida pela Google, mas, atualmente, é mantida pela Open Handset Alliance (OHA). Todas as aplicações para o Android desenvolvidas por essa plataforma foram criadas com a linguagem Java, a qual facilita sua programação, quer seja em Java, quer em outras linguagens, tais como $\mathrm{C}++$ e $\mathrm{C \#}$.

A primeira versão do aplicativo ficou pronta no dia 16 de agosto de 2016 e, após alguns pequenos ajustes, começou a ser testada, efetivamente, em sala de aula. Depois de algumas sugestões e discussões, o nome "Foca na Comb" foi adotado. Para a realização da pesquisa, os alunos e seus responsáveis assinaram um Termo de Consentimento Livre e Esclarecido - TCLE. O aplicativo foi utilizado em sala de aula de três turmas do segundo ano do Ensino Médio, de uma escola particular localizada na cidade de Ipatinga, estado de Minas Gerais. A sequência de atividades didáticas em que o aplicativo está estruturado foi construída contendo oito desafios, organizados em ordem crescente de grau de dificuldade, de acordo com a organização apresentada no Quadro 1, no Quadro 2 e na figura 1.

\section{Figura 1 - Telas iniciais e Desafio II do "Foca na Comb"}

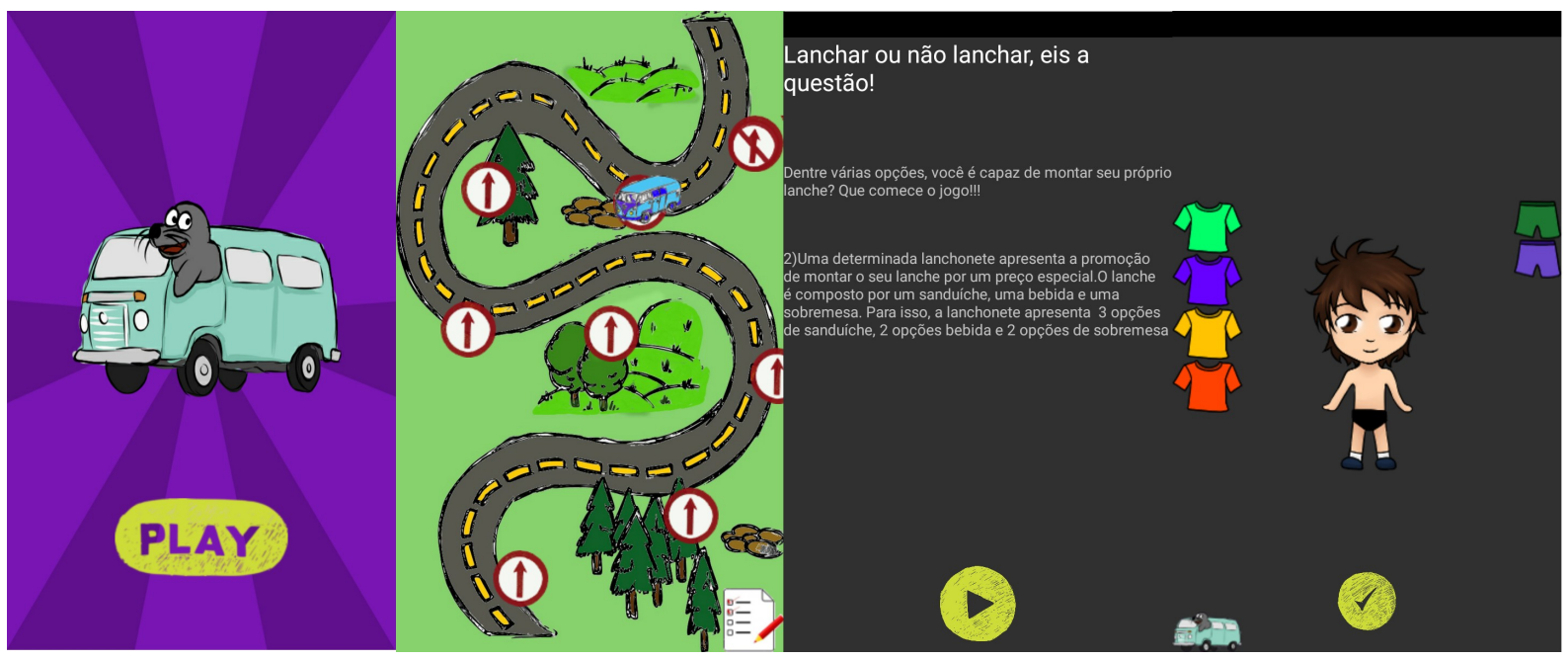

Fonte: Elaborado pelo Autor 
Quadro 1 - Resumo dos desafios e objetivos - Parte 1

\begin{tabular}{|c|c|c|}
\hline Desafio & Titulo & Objetivos \\
\hline I & $\begin{array}{l}\text { Princípio } \\
\text { Aditivo e Princípio } \\
\text { Multiplicativo }\end{array}$ & $\begin{array}{l}\text { Criar estratégias para agrupar elementos, com auxílio de } \\
\text { esquemas e da "árvore de possibilidades", para que os } \\
\text { alunos percebam a adição e a multiplicação como } \\
\text { ferramentas de grande utilidade dentro do processo de } \\
\text { contagem. Com isso, associa-se o "ou" para o "Princípio } \\
\text { Aditivo" e o "e" para o "Princípio Multiplicativo". }\end{array}$ \\
\hline II & $\begin{array}{l}\text { Princípio } \\
\text { Aditivo e Princípio } \\
\text { Multiplicativo }\end{array}$ & $\begin{array}{l}\text { Através de um desafio mais elaborado, fixar os conceitos } \\
\text { associados ao desafio I, criar estratégias para agrupar } \\
\text { elementos, com auxílio de esquemas e da "árvore de } \\
\text { possibilidades", para que os alunos percebam a adição e } \\
\text { a multiplicação como ferramentas de grande utilidade } \\
\text { dentro do processo de contagem. Com isso, associa-se o } \\
\text { "ou" para o "Princípio Aditivo" e o "e" para o } \\
\text { "Princípio Multiplicativo". }\end{array}$ \\
\hline III & $\begin{array}{l}\text { Permutação } \\
\text { Simples e Permutação } \\
\text { com Repetição }\end{array}$ & $\begin{array}{l}\text { Introduzir o conceito de permutação como troca aleatória } \\
\text { de posição de elementos, mostrar as diferenças quando os } \\
\text { elementos são todos distintos e quando aparecem } \\
\text { elementos iguais dentro de um agrupamento e como criar } \\
\text { estratégias para contar o número total de configurações } \\
\text { que podem ser criadas a partir dessa troca aleatória de } \\
\text { posição de elementos. }\end{array}$ \\
\hline IV e V & $\begin{array}{l}\text { Arranjo Simples e } \\
\text { Combinação Simples }\end{array}$ & $\begin{array}{l}\text { Perceber que, tendo um grupo de } n \text { elementos, é possível } \\
\text { reagrupar esses elementos em subgrupos com } p \text { elementos, } \\
\text { com } p \text { menor ou igual a } n \text {. Mostrar quando a ordem dos } \\
\text { elementos deve ser considerada importante ou não, dentro } \\
\text { dos novos agrupamentos. Criar estratégias de resolução, } \\
\text { sem mencionar as fórmulas matemáticas que envolvem os } \\
\text { conceitos de arranjo simples e combinação simples, } \\
\text { podendo utilizar as quatro operações básicas e o conceito } \\
\text { de Fatorial para resolver o desafio. }\end{array}$ \\
\hline
\end{tabular}

Fonte: Elaborado pelo Autor.

\section{ANÁLISE E RESULTADOS}

Após a elaboração dos desafios e montagem do aplicativo, foram realizados os encontros com os alunos e posteriormente, algumas melhorias no aplicativo propostas por eles. Após as mudanças e adaptações necessárias no aplicativo, o "Foca na Comb" foi novamente disponibilizado para que os estudantes envolvidos na pesquisa pudessem testá-lo novamente.

Foram analisados os dados gerados pelas anotações e gravações de áudio, coletados nos encontros de agosto e setembro de 2016, bem como dos questionários aplicados aos alunos envolvidos nesta pesquisa.

O segundo ano do Ensino Médio era composto por um total de 141 alunos, divididos em três turmas, mas apenas 73 alunos participaram efetivamente da pesquisa por terem apresentado o TCLE devidamente preenchido e assinado. 


\section{Quadro 2 - Resumo dos desafios e objetivos - Parte 2}

\begin{tabular}{|l|l|l|}
\hline Desafio & \multicolumn{1}{|c|}{ Titulo } & \multicolumn{1}{c|}{ Objetivos } \\
\hline VI & $\begin{array}{l}\text { Combinação } \\
\text { Simples } \\
\text { desenvolvidos nos desafios IV e V, especialmente em } \\
\text { situações-problema quando a ordem dos elementos não é } \\
\text { importante dentro do agrupamento. Criar estratégias de } \\
\text { resolução, sem mencionar fórmula matemática que envolve } \\
\text { o conceito de combinação simples, podendo utilizar as } \\
\text { quatro operações básicas e o conceito de Fatorial para } \\
\text { resolver o desafio. }\end{array}$ \\
\hline VII & $\begin{array}{l}\text { Permutraç um novo caso de Permutação, onde a disposição de } \\
\text { Circular }\end{array}$ & $\begin{array}{l}\text { n elementos dentro de um grupo devem estar organizados em } \\
\text { forma de círculo. Criar estratégias de resolução, sem mencionar } \\
\text { a fórmula matemática que envolve o conceito Permutação } \\
\text { Circular, podendo utilizar as quatro operações básicas e o } \\
\text { conceito de Fatorial para resolver o desafio. }\end{array}$ \\
\hline VIII & $\begin{array}{l}\text { Através de um desafio mais elaborado, fixar os conceitos } \\
\text { desenvolvidos nos desafios IV, V e VI, especialmente em } \\
\text { situações-problema quando a ordem dos elementos não é } \\
\text { importante dentro do agrupamento. Criar estratégias de } \\
\text { resolução, sem mencionar a fórmula matemática que } \\
\text { Simples }\end{array}$ & $\begin{array}{l}\text { envolve o conceito combinação simples, podendo utilizar } \\
\text { as quatro operações básicas e o conceito de Fatorial para } \\
\text { resolver o desafio. }\end{array}$ \\
\hline
\end{tabular}

Fonte: Elaborado pelo Autor.

$\mathrm{Na}$ análise da transcrição dos áudios, ficou destacada a iniciativa apresentada pelos alunos para resolver os desafios, mesmo que esse fato não tenha garantido que eles resolveram todos os desafios corretamente. Erros e acertos fizeram parte do processo. Os alunos desenvolveram estratégias próprias para chegar à solução de cada desafio proposto no aplicativo, por meio da discussão em grupo. Na resolução dos desafios I, II e III do "Foca na Comb", o professor-pesquisador não fez qualquer tipo de interferência no trabalho dos grupos. Nas três turmas do segundo ano, onde os encontros foram realizados, foi perceptível o desejo dos alunos de resolver cada etapa de cada desafio sem a ajuda do professor.

No encontro realizado em que foram propostos os desafios V e VII do aplicativo "Foca na Comb", devido ao fato destes envolverem problemas mais elaborados em relação aos desafios do encontro anterior, algumas perguntas foram feitas ao professor-pesquisador, porém ele não as respondia diretamente e, sim, com outra pergunta, ou com uma questão investigativa para motivá-los a pensar um pouco mais, ou promover a reflexão em grupo. Como os desafios $\mathrm{V}$ e VII tratam de Combinação Simples e Arranjo Simples e Permutação Circular, as discussões entre os grupos foram mais calorosas do que as discussões feitas nos desafios I, II e III, que são compostas de problemas básicos de Princípio Aditivo e Multiplicativo e Permutações Simples e com Repetição.

Outro importante destaque, nesta análise, é a descoberta de novos conceitos promovida pela discussão em grupo. Isso ficou evidente no debate entre os grupos e na discussão geral 
com todos os grupos. Como exemplo, pode-se citar o desafio III, que propõe descobrir o total de anagramas da palavra FACA e FOCA. Na discussão promovida em cada grupo, os próprios alunos concluíram que 4 ! é o total de anagramas da palavra FOCA. Já a palavra FACA possui 12 anagramas, que é $4 ! / 2$ !, total de letras que a palavra possui dividido pelo total de repetições da letra A.

Outro exemplo curioso foi observado na resolução do desafio V. Na maioria dos grupos foi observado que a mudança da ordem entre os elementos dentro de um determinado grupo não era importante para resolver o problema proposto no item (a), isto é, o fato de sortear os mesmos quatro elementos em ordem diferentes não cria um novo grupo de contemplados com a bolsa de estudos. Por outro lado, no item (b), a situação muda, pois dependendo da ordem do sorteio, cada sorteado é premiado com uma porcentagem diferente da bolsa de estudos, assim, tem-se que a ordem de sorteio entre os elementos de um determinado grupo é importante. Mesmo sem saber, os alunos haviam descoberto por meio da discussão uma das principais diferenças entre Combinação Simples e Arranjo Simples, como também no caso dos anagramas da palavra FACA e FOCA, em que ficou estabelecida a diferença básica entre Permutação Simples e a Permutação com Repetição.

Vale destacar que, em alguns momentos, observou-se que a discussão não ficou limitada apenas entre os integrantes de um mesmo grupo, mas foi observada também entre os grupos. Essa dinâmica não foi interrompida pelo professor-pesquisador, pois, apesar de alguns alunos estarem interessados em apenas saber se o outro grupo havia resolvido os desafios, a maioria dos grupos estava interessada em saber como cada um havia pensado, e fazia comparação entre as linhas de raciocínio utilizadas. Para os alunos que apenas queriam saber as respostas dos desafios, o professor os motivou e os estimulou a pensarem e a discutirem cada desafio com o seu respectivo grupo.

Outras perguntas interessantes surgiram, como por exemplo, a de um determinado aluno, baseado no desafio II, item (d): "E se as opções do pacote 1 pudessem ser misturadas com as opções do pacote 2? Então, quantas opções de lanche, escolhendo uma opção de sanduíche, uma opção de bebida e uma opção de sobremesa poderiam ser montadas?" Alguns instantes depois, um integrante de outro grupo respondeu: “360 é a resposta!” O professor-pesquisador perguntou: "Como você chegou a esse resultado?" Ele respondeu: "Como é possível misturar as opções do pacote 1 com o pacote 2, para montar o lanche, teremos 9 opções de sanduíches, 8 opções de bebida e 5 opções de sobremesa, isto é, 9. 8. 5=360". O professor perguntou para a turma: "A resposta está correta?" A turma respondeu: "Sim!" Nesse momento, ficou claro que os alunos participantes desse diálogo haviam compreendido com clareza o Princípio Aditivo e o Princípio Multiplicativo, pois não foi necessária a intervenção do professor para responder a pergunta feita pelo aluno. Momentos como esse ocorreram também nas outras duas turmas. $\mathrm{O}$ exemplo acima foi citado para mostrar o envolvimento dos alunos no diálogo. A turma estava empenhada em resolver os desafios e a responder os questionamentos que iam surgindo.

$\mathrm{O}$ aplicativo foi bem aceito pelos alunos e tornou as aulas mais dinâmicas e atraentes para a compreensão de conceitos ligados à Análise Combinatória, fato que pode ser observado 
na figura 2. O jogo "Foca na Comb", juntamente com o código fonte está disponibilizado como produto da dissertação de Mestrado em Ensino de Ciências e Matemática na biblioteca da PUC Minas e no site do programa.

Figura 2 - Alunos em sala de aula

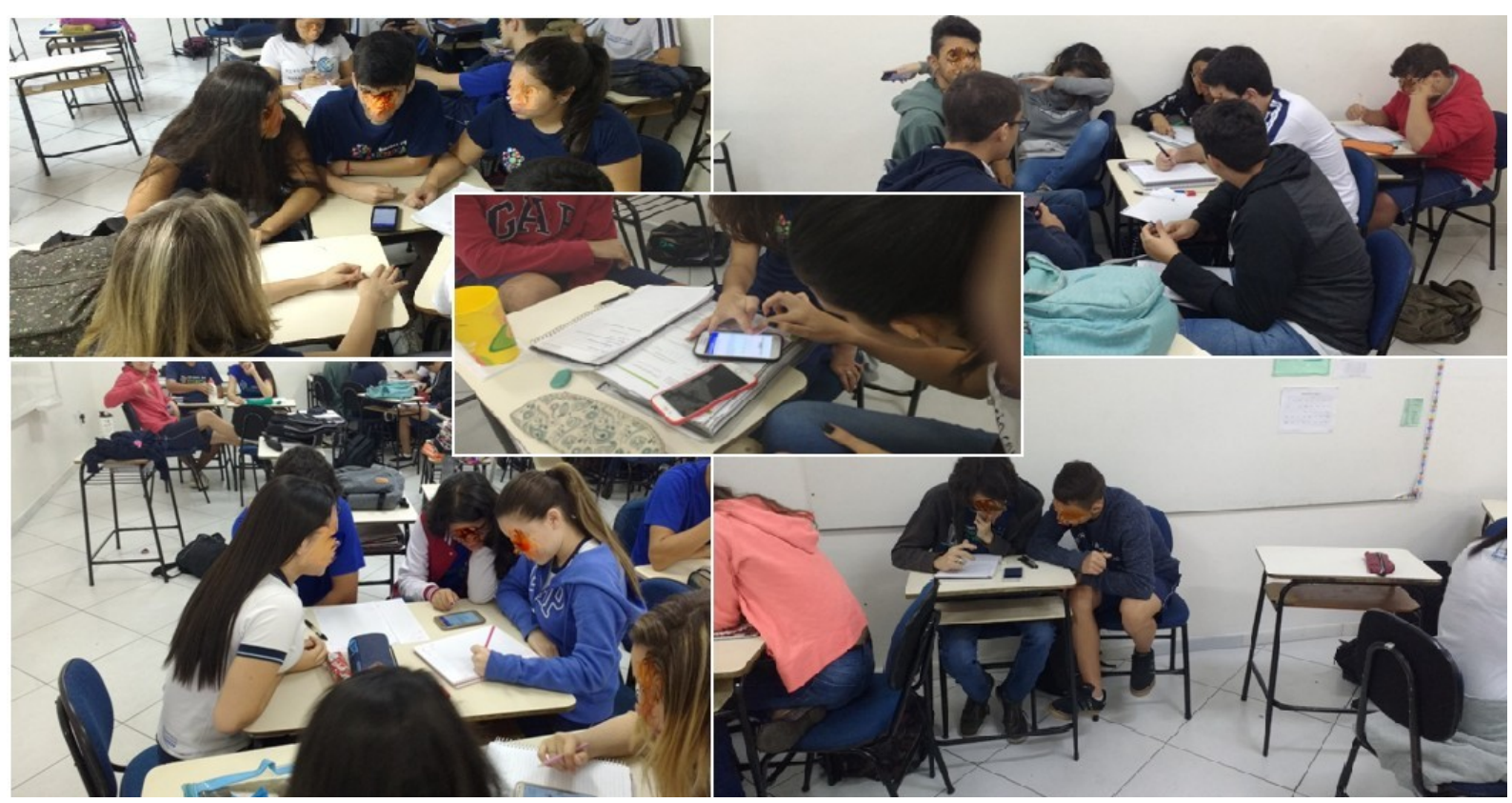

Fonte: Acervo do Autor. 


\section{CONSIDERAÇÕES FINAIS}

O desenvolvimento do presente estudo possibilitou verificar, mesmo que em uma escala menor, que o ensino da Análise Combinatória, por meio de jogos, facilitou o entendimento e a compreensão do tema pelos alunos. Esse fato corrobora Silva (2013), que afirma que o ensino de Análise Combinatória é muito mais do que simplesmente decorar fórmulas matemáticas. As diferenças entre a teoria e a prática, quando se compara o que se aprende em sala de aula com as situações reais vividas pelo aluno em seu cotidiano, evidenciam uma melhoria no processo de ensino e aprendizagem da Matemática.

Refletindo sobre esse cenário, pode-se pensar em metodologias e práticas pedagógicas que promovam um ambiente favorável ao aprendizado em sala de aula, por meio de atividades que favoreçam a investigação e o interesse pela descoberta do "novo".

Assim, chegou-se à conclusão que o uso de novos recursos tecnológicos pode contribuir para mudar o ensino da Análise Combinatória sem o uso de memorizações de fórmulas.

Até o desenvolvimento dessa pesquisa, o professor-pesquisador havia trabalhado com o ensino de Análise Combinatória em turmas de segundo ano do Ensino Médio, na mesma escola em que essa pesquisa foi realizada, entre os anos de 2009 e 2015, utilizando, exageradamente, as fórmulas da Permutação, Arranjo e Combinação e a maioria deles não demonstrava interesse sobre o assunto. Após a experiência da utilização do "Foca na Comb" e de aulas dinâmicas, o professor-pesquisador percebeu que, num primeiro momento, houve uma melhoria no processo de construção do conhecimento, pois foi observado o interesse dos alunos em aprender.

Apesar deste estudo relatar uma experiência que apresentou bons resultados, muito ainda é preciso fazer para mudar o ensino da Análise Combinatória. O aplicativo "Foca na Comb" é uma sugestão metodológica que foi disponibilizada como produto de uma dissertação do Programa de Mestrado em Ensino na área de concentração de Ciências e Matemática da PUC Minas, com a finalidade de promover o acesso e utilização por outros docentes. Espera-se, que esses usuários façam sugestões e/ou proponham melhorias para que esse aplicativo possa ser uma ferramenta que proporcione mudanças positivas para o ensino de Análise Combinatória. Para trabalhos futuros, fica como sugestão a realização da portabilidade do jogo para o sistema operacional móvel da Apple, IOS, dado que o código fonte do aplicativo foi disponibilizado. 


\section{REFERÊNCIAS}

BARBOSA, Sandra Lucia Piola; CARVALHO, Túlio Oliveira de. Jogos matemáticos como metodologia de ensino aprendizagem das operações com números inteiros. Projeto de Intervenção Pedagógica na Escola apresentado ao Programa de Desenvolvimento Educacional da Universidade Estadual de Londrina (UEL), Londrina, 2008.

CABRAL, Marcos Aurélio. A utilização de jogos no ensino de matemática. 2006. Monografia (Conclusão de Curso) - Universidade Federal de Santa Catarina.

CAVALCANTE, Nahum Isaque dos Santos. O ensino de matemática no contexto das novas tecnologias: refletindo as potencialidades do uso de softwares dinâmicos como recurso em sala de aula. In: V CONNEPI-2010. Maceió: [s.n.], 2010.

D’AMBROSIO, Ubiratan. Educação Matemática: da teoria à prática. Campinas: Papirus Editora, 2014. (Trabalho original publicado em 1996).

FIORENTINI, Dario; LORENZATO, Sergio. Investigação em educação matemática: percursos teóricos e metodológicos. 3. ed. Campinas, SP: Autores Associados, 2012.

JUCÁ, Sandro César Silveira. A relevância dos softwares educativos na educação profissional. Ciências \& Cognição, Instituto de Ciências Cognitivas, v. 8, p. 22-28, 2006.

LIMA, Tereza Raquel Couto de. Ensinando e aprendendo análise combinatória através da leitura e resolução de problemas e da construção de enunciados. $2011.148 \mathrm{f}$. Dissertação (Mestrado em Ensino de Ciências e Matemática) - Pontifícia Universidade Católica de Minas Gerais, Belo Horizonte.

PERIUS, Ana Amélia Butzen. A tecnologia aliada ao ensino da matemática. 2012. 55 f. Monografia (Especialização) — Universidade Federal do Rio Grande do Sul, Cerro Largo.

RIBEIRO, Luis Roberto de Camargo. Aprendizagem baseada em problemas (PBL): uma experiência no ensino superior. São Carlos: EdUFSCar, 2008.

ROMERO, Danielle D'avila. O ensino da matemática através da resolução de problemas. In: CONGRESSO NACIONAL DE EDUCAÇÃO EDUCERE, 7., 2007, Vitória. Anais eletrônicos... Curitiba: PUCPR, 2007.

SANTOS, Rosana Cerqueira dos. Brincando e aprendendo: A importância do brincar no desenvolvimento cognitivo, afetivo e social da criança na educação infantil. 2010. Monografia (Conclusão de Curso) - Universidade Estadual da Bahia. Disponível em: <https:http: //www.uneb.br/salvador/dedc/files/2011/05/Manografia-Rosana-Cerqueira-dos-Santos.pdf>.

Acesso em: 13 set. 2017.

SILVA, José Carlos Thompson da. Jogo de combinatória: Uma proposta para a formação inicial de professores. In: ENCONTRO NACIONAL DE ESTUDANTES DE PÓSGRADUAÇÃO EM EDUCAÇÃO MATEMÁTICA, 17., Goiânia. Anais eletrônicos... Goiânia: IFES, 2013. Disponível em: <http://ocs.ifes.edu.br/index.php/ebrapem/xvii_ebrapem/ paper/view/829>. Acesso em: 06 dez. 2016.

UNESCO. Diretrizes de políticas para a aprendizagem móvel. 2014. Disponível em: <http: //unesdoc.unesco.org/images/0022/002277/227770por.pdf>. Acesso em: 30 jul. 2017. 